\title{
THE RADIOLOGICAL FEATURES OF SYPHILITIC AORTIC INCOMPETENCE
}

\author{
BY \\ W. G. SMITH* AND J. C. LEONARD $\dagger$ \\ From the National Heart Hospital \\ Received June 26, 1958
}

Linear calcification of the ascending aorta is an almost specific radiological sign of syphilitic aortitis. If carefully sought, it can be found in about 40 per cent of patients with this disease (Thorner and Carter, 1948). It is therefore a valuable aid in the differential diagnosis of aortic incompetence, but even now its value is not fully recognized. Stroud (1950) and Scherf and Boyd (1948) do not mention the sign in their text-books. In his recent text-book on 'Principles of Chest X-ray Diagnosis', Simon (1956) does not specify the site of calcification of the aorta in syphilitic aortitis. In the course of a recent extensive survey of syphilitic aortic incompetence (Leonard and Smith, 1957; Smith, 1957) the value of radiological examination was apparent; an attempt is here made to assess more fully the contribution that this investigation can make towards accurate clinical diagnosis.

\section{Material AND Methods}

The clinical features, prognosis, and response to treatment were studied in a series of 422 patients with syphilitic aortic incompetence. The diagnosis was made during the years 1926-57 at the National Heart Hospital; The London Hospital; The Middlesex Hospital; The Royal Infirmary, Aberdeen; The Norfolk and Norwich Hospital; St. Bartholomew's Hospital; and the Royal Infirmary, Cardiff. The criteria of selection were strict and have been previously detailed (Leonard and Smith, 1957). For the purpose of studying prognosis all patients with saccular aneurysm and gross aortic dilatation were excluded. Of the 123 survivors, 50 have been personally examined on one or more occasions.

The chest radiograms of 83 patients have been carefully studied. These include the 50 patients, that were personally examined, and a further 33, whose radiograms were available and were technically satisfactory. All except 10 of the patients had two postero-anterior (P-A) films taken, one the conventional six-foot teleradiogram and the second an over-penetrated teleradiogram with a stationary grid. The second P-A view is very helpful in detecting calcium in the aorta or elsewhere and in outlining the size and shape of the aorta. It also shows the shadow of an enlarged left atrium, lying within the right border of the heart. Bilateral oblique views were taken in 30 patients. Screening with a barium swallow was carried out in 35 patients. Serial radiograms were available in the majority.

The following points were examined in the radiograms.

(1) The cardio-thoracic ratio.

(2) The size and shape of the aorta. The size was graded as normal, slightly dilated, moderately dilated, or considerably dilated.

(3) The size of the left ventricle similarly graded.

* Present address-Sully Hospital, Penarth, Glamorgan.

† Present address-Manchester Royal Infirmary. 
(4) The presence of calcification in the ascending aorta, the aortic arch, the descending aorta, and the aortic valve.

(5) The presence of hilar or pulmonary clouding, pleural effusion, or the septal lines of Kerley (1933).

The results of screening were added when available, but on the whole little additional information was obtained. In two cases aortic valve calcification was confirmed and in some a better estimate of left ventricular size could be obtained on the screen. Conversely left atrial enlargement was more accurately diagnosed in an over-penetrated P-A film. An enlarged left ventricle may displace the left atrium backwards and so simulate left atrial enlargement on screening.

The findings are shown in Table I.

\section{RESULTS}

Linear calcification of the ascending aorta occurred 32 times $(39 \%)$ and in 10 patients $(12 \%)$ the calcification was confined to the ascending aorta. Necropsies, performed on 9 of these patients, confirmed the diagnosis in all. Representative examples are seen in Fig. 1 and 2. The radiogram in Fig. 2 was taken in 1956 and shows calcification in the ascending aorta, arch, and descending aorta. Syphilitic aortic incompetence had been diagnosed in this patient in 1932 at the age of 37 years. Dilatation and sometimes irregularity of the aorta were usually associated with linear calcification of the ascending aorta, but in two patients the aorta was of normal size.

TABLE I

\section{SUMMARY OF FINDINGS}

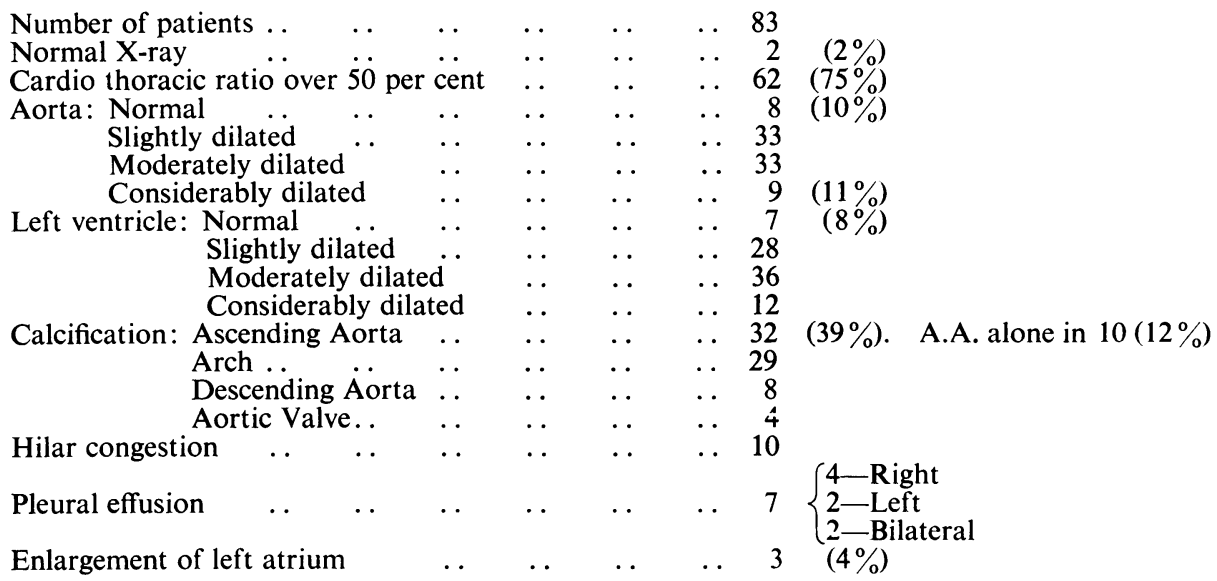

As calcification presumably results from atherosclerotic degeneration superimposed on syphilitic aortitis, it would be expected to occur more often in elderly patients and when the disease is of long standing. In this series the mean age of the patients with calcification of the ascending aorta was 62 years (the mean age of all 422 patients was 54 years). The youngest patient with calcification of the ascending aorta was aged 42 years.

The sex ratio of patients with calcification of the ascending aorta was 1.5 male to 1 female, compared with 2.4 male to 1 female in all 422 patients with syphilitic aortic incompetence. This slighter male preponderance occurred in spite of the fact that the older age groups contained a higher proportion of men. The difference may be explained by the fact that women were shown to have a better prognosis than men and are therefore more likely to develop calcification as a manifestation of chronicity of the disease. The absence of calcification of the ascending aorta cannot, of course, be taken as evidence against syphilitic aortitis. In this series five patients had calcification confined to the aortic arch.

The aorta and left ventricle were considered normal in 8 patients $(10 \%)$ and 7 patients $(8 \%)$ respectively. Two patients had entirely normal radiograms. This underlines the important clinical 


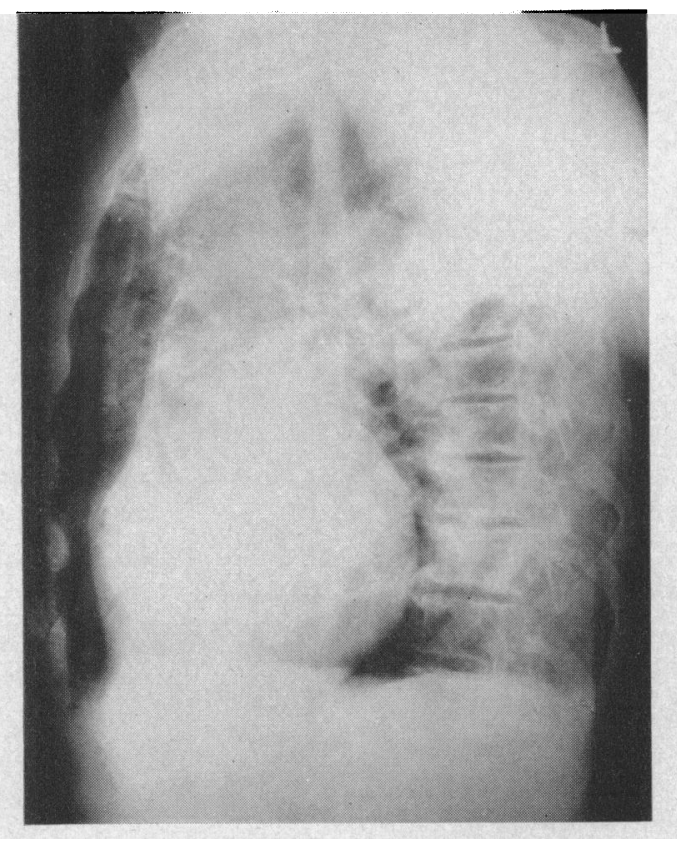

FIG. 1.-Lateral radiogram, showing calcification of the ascending aorta.

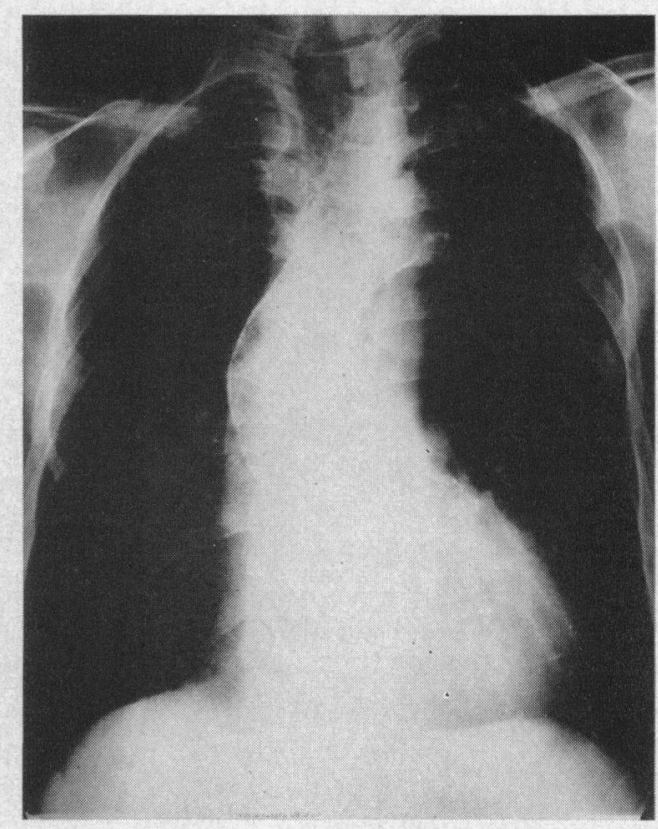

FIG. 2.-Over-penetrated postero-anterior radiogram, showing extensive calcification of the aorta, especially in its ascending portion.

fact that syphilitic aortitis need not produce any radiological abnormality, even when aortic incompetence is present. Kerley (1950) has pointed out that up to 30 per cent of patients may have a normal radiogram. The maximum incidence of normal radiograms will obviously be found in the earlier stages of the disease. When aortic incompetence has developed, an entirely normal radiogram is rare.

Slight enlargement of the left atrium was noted in three patients. Two of these had a wide bifid $P$ wave in the electrocardiogram, confirming the left atrial abnormality and one had a loud atrial sound (4th heart sound). An enlarged left atrium will always suggest mitral valve disease, but can also occur in other diseases producing left atrial stress, such as aortic valve disease, hypertension, and coronary artery disease (Wood, 1956; Cobbs et al., 1957).

The cardiothoracic ratio was greater than 50 per cent in 62 patients $(75 \%)$. However, this measurement is only a rough guide to heart size. It will obviously depend on chest capacity and on the phase of respiration. The woman with the largest ratio $(70 \%)$ had a very small chest and her valve lesion was moderate rather than gross.

\section{Discussion}

Calcification of the ascending aorta was first mentioned as a casual observation by Snellen (1939), but its significance was not then appreciated. In 1942 Schatzki stressed the significance of this sign. However, Blumenthal et al. (1944) thought the calcific deposits in the aorta were more often due to hypertension and arteriosclerosis than to syphilis.

Jackman and Lubert (1945) examined the radiograms of 66 patients with syphilitic aortitis confirmed at autopsy. No special radiographic techniques were used to demonstrate calcification, which was noted in the ascending aorta in 22 per cent of patients. The mean age of these patients was 57 years compared with 52 years in those without calcification. 62 patients with severe atherosclerosis were also investigated. Calcification of the ascending aorta was noted in only 2 
$(3 \%)$. Both these patients had associated calcification in the aortic arch. Using special radiographic techniques, Thorner and Carter (1948) demonstrated calcification of the ascending aorta in 39 per cent of 38 consecutive patients with syphilitic aortitis: a review of the routine radiograms of 111 cases showed an incidence of 14 per cent.

Leighton (1948) examined the radiograms of 18 patients with syphilitic aortitis confirmed at necropsy: nine had calcification of the ascending aorta. Of a further 39 , in whom syphilitic aortitis had been diagnosed clinically, the ascending aorta was calcified in 43 per cent. He also studied the radiograms of 400 non-syphilitic patients of corresponding age and sex: calcification of the ascending aorta was present in two $(0.5 \%)$.

Wolkin (1954) found calcification of the ascending aorta in $54(57 \%)$ of 95 patients with syphilitic aortitis. In 11 the calcification was confined to the ascending aorta. The average age of these patients was 60 years.

McCann and Porter (1956) reported calcification of the ascending aorta in 19 patients with syphilitic aortitis, and in 12 the calcification was confined to the ascending aorta.

The reported findings thus indicate that calcification of the ascending aorta is a nearly specific sign of syphilitic aortitis. It rarely occurs in severe atherosclerosis and hypertension and, if so, the aortic calcification is likely to be widespread and to occur only to a slight degree in the ascending portion. In syphilis it is a common finding especially in older patients and in the present investigation the incidence of 39 per cent is the same as the figure obtained by Thorner and Carter (1948). It should be emphasized that early calcification of the ascending aorta can only be detected with the help of careful radiography. Special views including over-penetrating P-A and oblique views and tomograms are very helpful, and should be employed before linear calcification is pronounced absent.

In this investigation dilatation and loss of parallelism of the aorta was usually present in patients with aortic calcification, but in two with obvious calcification, there was no dilatation or irregularity of the aortic lumen. Loss of parallelism of the aorta, if present, is a valuable sign of syphilitic aortitis and does not occur in atherosclerosis (Kerley, 1950). The various aortic measurements recommended in the past (Vaquez and Bordet, 1920; Kemp and Cochems, 1937) can have little place in the diagnosis of syphilitic aortitis in view of the varying degrees of aortic dilatation in hypertension and arteriosclerosis, non-syphilitic aortic valve disease, and congenital anomalies of the aorta. Angiocardiography has been advised to show the calibre of the aorta (Dotter and Steinberg, 1949) but can rarely be justified. Increased density of the aorta has been said to be evidence of syphilitic aortitis, but is equally common in hypertension and arteriosclerosis.

The most important clinical application of calcification of the ascending aorta is in the ætiological diagnosis of aortic incompetence. A syphilitic ætiology can be diagnosed with confidence if other signs of syphilis (particularly neurosyphilis) are present, or if the serological reactions, including the treponemal immobilisation test, are positive. In addition, the erythrocyte sedimentation rate is raised in about 80 per cent of patients with untreated syphilitic aortic incompetence without congestive heart-failure (Leonard and Smith, 1957), but is usually normal in other varieties of aortic incompetence. Calcification of the ascending aorta is a very useful confirmatory sign and occasionally may be the only evidence of a syphilitic ætiology.

\section{SUMMARY}

The chest radiograms of 83 patients with syphilitic aortic incompetence have been studied.

The incidence of linear calcification of the ascending aorta was 39 per cent and this can be accepted as a reliable and almost specific sign of syphilitic aortitis. Special radiographic techniques are often necessary to demonstrate calcification of the ascending aorta in its earliest form.

The sign is of particular value in determining the aetiology of aortic incompetence and should be considered in conjunction with the clinical features, the serological reactions, and the erythrocyte sedimentation rate. 
We wish to thank Dr. Evan Bedford, Dr. Frederick Bowie, Dr. Wallace Brigden, Dr. James Campbell, Dr. Maurice Campbell, Dr. Robert Duthie, Dr. William Evans, Professor Harold Fullerton, Dr. Graham Hayward, Mr. Ambrose King, Dr. Kenneth Latter, Dr. Lawson McDonald, Dr. Wilfrid Oliver, Dr. William Phillips, Dr. Arthur Thomas and Dr. Paul Wood for permission to study patients under their care. It is a great pleasure to thank Dr. Peter Kerley for his valuable advice.

Mrs. Olive Connolly kindly provided the photographs.

\section{REFERENCES}

Blumenthal, H. T., Lansing, A. I., and Wheeler, P. A. (1944). Amer. J. Path., $20,665$.

Cobbs, B. W., Shillingford, J. P., and Steiner, R. E. (1957). Brit. Heart J., 19, 495.

Dotter, C. T., and Steinberg, I. (1949). Ann. intern. Med., 30, 1104.

Jackman, J., and Lubert, M. (1945). Amer. J. Roentgenol., 53, 432.

Kemp, J. E., and Cochems, K. D. (1937). Amer. J. Syph., 13, 297.

Kerley, P. (1933). Brit. med. J., 2, 594.

(1950). A Textbook of X-ray Diagnosis by British Authors. 2nd ed. Vol II, London.

Leighton, R. S. (1948). Radiol., 51, 257.

Leonard, J. C., and Smith, W. G. (1957). Lancet, 1, 234.

McCann, J. S., and Porter, D. C. (1956). Brit. med. J., 1, 826.

Schatzki, R. (1942). New Engl. J. Med., 227, 24.

Scherf, D., and Boyd, L. J. (1948). Cardiovascular Diseases. 2nd ed. New York.

Simon, G. (1956). Principles of Chest X-ray Diagnosis. London.

Smith, W. G. (1957). M.D. Thesis. Univ. of Aberdeen.

Snellen, H. A. (1939). Year Book of Radiology. Chicago.

Stroud, W. D. (1950). Diagnosis and Treatment of Cardiovascular Disease. Vol. I. Philadelphia.

Thorner, M. C., and Carter, R.A. (1948). Amer. Practit., 2, 301.

Vaquez, H., and Bordet, E. (1920). The Heart and Aorta; Studies in Clinical Radiology. Yale.

Wolkin, A. (1954). Radiol., 62, 101.

Wood, P. (1956). Diseases of the Heart and Circulation. 2nd ed. London. 